\title{
Ultrasonic Effects on Electroorganic Processes. XIII. A Role of Ultrasonic Cavitation in Electrooxidative Polymerization of Aniline
}

\author{
Mahito ATOBE, Takeshi KABURAgI, and Tsutomu NONAKA* \\ Department of Electronic Chemistry, Tokyo Institute of Technology (4259 Nagatsuta, Midori-ku, Yokohama, \\ Kanagawa 226-8502, Japan)
}

Received May 24, 1999 ; Accepted July 5, 1999

\begin{abstract}
As a practical guideline, it was indicated that aniline is electrooxidatively polymerized in an acidic electrolytic solution under irradiation of ultrasound with a power higher than the cavitation threshold to form a highly uniform and dense polyaniline film available for electronic devices such as an electrolytic capacitor.
\end{abstract}

Key Words : Electrooxidative Polymerization, Polyaniline Film, Ultrasonic Cavitation Threshold

\section{Introduction}

Electroactive films of aromatic polymers formed electrooxidatively on anodes have received much attention from not only fundamental but also practical aspect, since they exhibit peculiar properties such as electroconductivity, semiconductivity, redox, doping, electrochromism, etc. Generally, properties of polymers are originated from their chemical (molecular) and physical (morphological) structures. In this point of view, it should practically be required that the structures of the electroactive polymer films can be controlled purposively for their utilization. However, few methods have been developed for controlling the physical structures so far, though the chemical ones can easily be controlled by changing molecular structures of the corresponding monomers and by selecting electrolytic conditions and procedures for the polymerization.

In our previous work ${ }^{1)}$ it was found that an extremely dense polyaniline film with a smooth surface can be formed under ultrasonic irradiation, however the mechanism of this significant ultrasonic effect has not been clarified so far. The high density polyaniline film seems to be indispensable for manufacturing a high performance electrolytic capacitor. Consequently, a practical guideline for preparing the high density film using the ultrasonic effect should be needed. In a response to this requirement, in this paper, a role of ultrasonic effect on the electrooxidative polymerization is demonstrated to give the guideline and to discuss preliminarily the mechanism.

\section{Experimental}

The electrooxidative polymerization of aniline was carried out by a cyclic potential-scanning method ${ }^{1,2)}$ under the following electrolytic conditions : Anode and cathode, Pt plates $(1 \times 1 \mathrm{~cm})$; cell, undivided type ; temperature, $25 \pm 1{ }^{\circ} \mathrm{C}$; electrolyte, $0.1 \mathrm{M}(\mathrm{M}=\mathrm{mol}$. $\left.\mathrm{dm}^{-3}\right)$ aniline $/ 4 \mathrm{M} \mathrm{HCl}\left(100 \mathrm{~cm}^{3}\right.$ of aqueous solution) ; potential-scanning range, $0.0-1.0 \mathrm{~V}$ vs. SCE; scanning rate, $0.1 \mathrm{Vs}^{-1}$. An ultrasonic stepped horn (a titanium alloy rod with $1.3 \mathrm{~cm}$ diameter) connected with a PZT oscillator $(20 \mathrm{kHz})$ was inserted into the solution. The output power of ultrasound was determined by calorimetry. ${ }^{3)}$ The anode (working electrode) surface was positioned perpendicularly to the propagating direction of ultrasonic wave, $2.0 \mathrm{~cm}$ apart from the top of the horn. A cavitation intensity index was monitored with a cavitation meter (Arock Industrial Co., Ltd., Model KS-8201R). ${ }^{4}$ The polyaniline film deposited on the anode was cathodically reduced at $0.0 \mathrm{~V}$ after the polymerization and then was subjected to SEM observation, and its thickness was measured by a displacement meter.

\section{Results and Discussion}

Figure 1 shows a relationship between cavitation intensity index monitored by a cavitation meter and ultrasonic power irradiated into the electrolytic solution for the polymerization of aniline. The index increases steeply at $>10 \mathrm{~W}$ with an increase in the power. It is noted that the ultrasonic cavitation in the

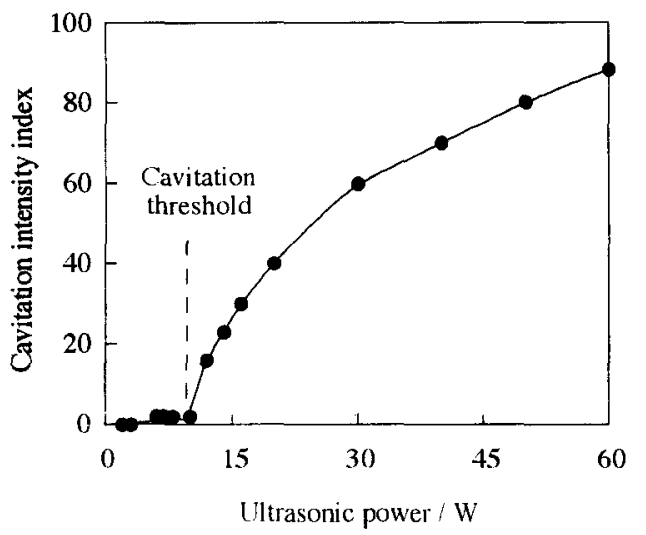

Fig. 1 Relationship between cavitation intensity index and ultrasonic power without electrolytic current in an solution for the polymerization of aniline. 
solution can take place at $>10 \mathrm{~W}$ while only the acoustic vibration of the solution at $<10 \mathrm{~W}$. The power of $10 \mathrm{~W}$ is a so-called cavitation threshold value and generally should depend on the whole geometry of apparatus and the nature of solution.

A polyaniline film electrooxidatively polymerized, regardless of ultrasonic irradiation, exhibits two sets of oxidation-reduction peaks on its cyclic voltammogram $^{1)}$ and each of them, particularly the first oxidation peak current $\left(i_{\mathrm{pa} 1}\right)$ is conveniently used as an indicator for amount of polyaniline deposited on the anode. ${ }^{5)}$ Figure 2 shows a relationship between the $i_{\text {pa } 1}$ of polyaniline formed at 50 cycles of potential scanning and the ultrasonic power irradiated into the electrolytic solution. The $i_{\text {pa } 1}$ decreases drastically at $10 \mathrm{~W}$ with an increase in the power. It is noticeable that the value of $10 \mathrm{~W}$ is equal to the cavitation threshold observed in Fig. 1. This fact indicates that the deposition rate of polyaniline is drastically decreased by an ultrasonic cavitation effect and is not affected by change in the power higher than threshold.

Figure 3 shows SEM surface photographs of polyaniline films prepared at various ultrasonic powers. Porous structures with grains are observed in the films at $0 \mathrm{~W}$ and $6 \mathrm{~W}$ below the cavitation threshold $(10 \mathrm{~W})$, while very smooth surfaces are observed at $17 \mathrm{~W}$ and $74 \mathrm{~W}$ over the threshold.

Approximate thickness and weight of the films could be measured by a displacement meter and from weight gain of the $\mathrm{Pt}$ anode, respectively, however, the electroconductivity could not because the films could not be torn off from the anode. Table 1 summarizes the thickness and the gravitational and electrochemical densities of the films prepared with and without ultrasonic irradiation. ${ }^{11}$ From the table, it is stated that the thin, uniform and dense film of polyaniline available for an electrolytic capacitor can be prepared using an ultrasonic effect. A further investigation for developing practical applications of the film is in progress.

In our previous work, ${ }^{4,6-10)}$ it was found that ordinary electrochemical oxidation and reduction of a variety of organic compounds without deposition of

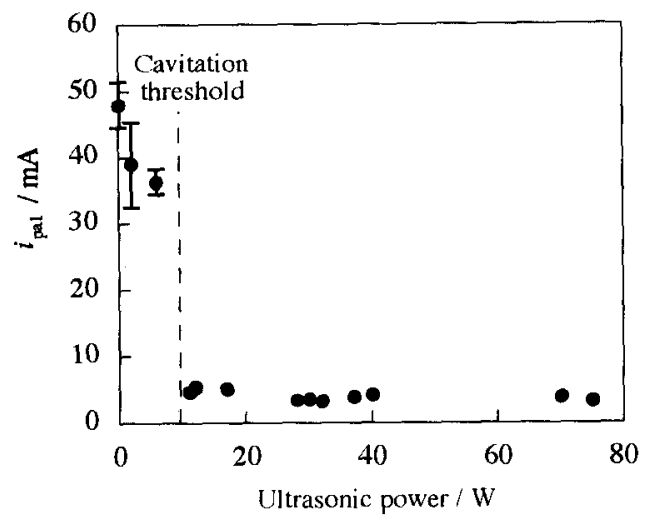

Fig. 2 Relationship between the first oxidation peak current $\left(i_{\text {pal }}\right)$ of polyaniline films prepared at 50 cycles of potential scanning and the ultrasonic power irradiated into the electrolytic solution during the polymerization. (a) $0 \mathrm{~W}$

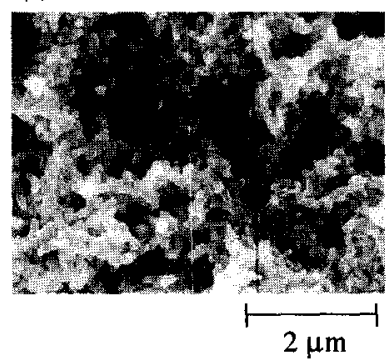

(c) $17 \mathrm{~W}$

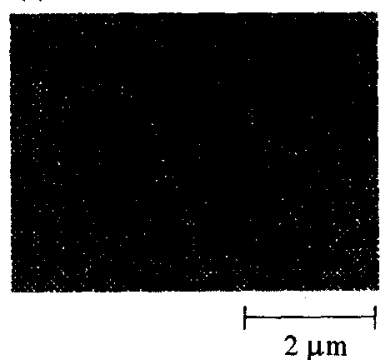

(b) $6 \mathrm{~W}$

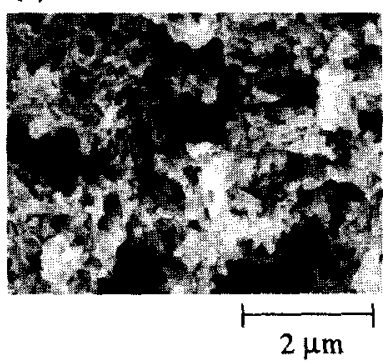

(d) $74 \mathrm{~W}$

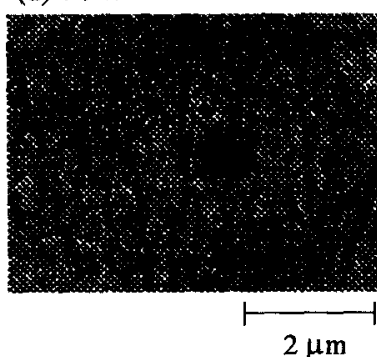

Fig. 3 SEM surface photographs of polyaniline filins prepared at 50 cycles of potential scanning at various ultrasonic powers.

Table 1 Thickness and density of polyaniline films prepared with and without ultrasonic irradiation.

\begin{tabular}{cccc} 
Ultrasonic & Thickness \\
$/ \mu \mathrm{m}$ & \multicolumn{2}{c}{ Density } \\
${ } }$ & & $\begin{array}{c}\text { Gravitational } \\
/ \times 10^{-2} \mathrm{~g} \mathrm{~cm}^{-3}\end{array}$ & $\begin{array}{c}\text { Electrochemical } \\
/ \mathrm{C} \mathrm{cm}^{-3}\end{array}$ \\
\hline With & 0.7 & 12 & 230 \\
Without & 19 & 2.6 & 100 \\
\hline
\end{tabular}

products on the working electrodes can be significantly accelerated under ultrasonic irradiation over the cavitation threshold, and this kind of ultrasonic effect could be experimentally and theoretically rationalized as being due to increase in mass transport across the electrode interface, because a similar acceleration effect could be also accomplished by mechanical agitation of the electrolytic solution. On the contrary, the deposition rate of polyaniline was remarkably decreased under ultrasonic irradiation over the threshold. In addition, polyaniline films with porous structure were formed under a mechanical stirring condition regardless of rotating speed $(2000 \mathrm{rpm}$ in maximum) of a propeller for agitating the electrolytic solution. These facts suggest that the mechanism of ultrasonic effect should be quite different between homogeneous and heterogeneous electrochemical processes without and with deposition of the products on the working electrodes, respectively. A further investigation from a mechanistic aspect is also in progress.

\section{Conclusion}

A practically useful guideline for electrooxidatively preparing thin, uniform and dense polyaniline films using an ultrasonic effect could be obtained; that is to irradiate ultrasounds with power to a necessary and 
sufficient minimum over the cavitation threshold. A similar guideline for electroactive films other than polyaniline, such as polythiophene and polypyrrole, has been obtained according to a preliminary investi. gation.

\section{Acknowledgement}

This study was financially supported by a Grant-inAid for Scientific Research on Priority Area (No. 282) from the Japanese Ministry of Education, Science, Culture and Sports.

\section{References}

1) M. Atobe, S. Fuwa, N. Sato, and T. Nonaka, Denki Kagaku (presently Electrochemistry), 65, 495 (1997).
2) N. Sato and T. Nonaka, Chem. Exp., 7, 433 (1992).

3) N. Enomoto, T.-H. Sung, and Z. Nakagawa, J. Mater. Sci., 27, 5239 (1992).

4) M. Atobe and T. Nonaka, Chem. Lett., 1997, 323.

5) L. J. Duic, Z. Mandic, and F. Kovacicek, J. Polymer Sci. Part A Polymer Chem., 32, 105 (1994).

6) M. Atobe and T. Nonaka, Nippon Kagaku Kaishi, 219 (1998) (in Japanese).

7) K. Matsuda, M. Atobe, and T. Nonaka, Chem. Lett., $1994,1619$.

8) M. Atobe, K. Matsuda, and T. Nonaka, Denki Kagaku (presently Electrochemistry), 62, 1298 (1994).

9) M. Atobe, K. Matsuda, and T. Nonaka, Electroanalysis, 8, 784 (1996).

10) H. Fujiwara, M. Aobe, H. Kanetsuna, and T. Nonaka, J. Chin. Chem. Soc., 45, 171 (1998). 